\title{
O TERRITÓRIO E A PAISAGEM: A FORMAÇÃO DA REDE DE CIDADES NO NORTE DO PARANÁ E A CONSTRUÇÃO DA FORMA URBANA ${ }^{1}$
}

\author{
THE TERRITORY AND THE LANDSCAPE: THE FORMATION OF THE CITIES' NETWORK \\ IN THE NORTH OF PARANÁ STATE AND THE CONSTRUCTION OF THE URBAN FORM
}

\author{
Renato Leão Rego \\ Arquiteto UEL, doutor pela Universidad Politécnica de Madrid. Departamento de Arquitetura e Urbanismo. \\ e-mail: rlrego@vem.br
}

Karin Schwabe Meneguetti

Arquiteta pela UFPR, mestre pela Universidade Estadual de Maringá (UEM) e doutoranda pela FAUUSP. e-mail: ksmeneguetti@uem.br

\section{RESUMO}

A Companhia de Terras Norte do Paraná foi responsável pela colonização de uma grande área nesse estado. De modo a atender a seus interesses econômicos - a venda de glebas rurais destinadas ao plantio de café - e de acordo com seu plano geral de ocupação desse território inexplorado, a companhia projetou e implantou uma rede de mais de 60 cidades entre os anos de 1930 e 1960.

Este artigo analisa a formação dessa rede urbana e os projetos das cidades novas que foram pautados por dois critérios gerais: situar-se no espigão e posicionar-se junto da linha férrea recém-construída. Nessa análise, atenta-se para os elementos básicos que ajudaram a definir cada nova forma urbana: a conformação urbana e a gênese de cada traçado, com sua particular relação com o sítio natural e os assentamentos vizinhos; a posição dos edifícios institucionais no tecido urbano; o desenho das vias e sua hierarquia; a forma e a localização dos espaços públicos e das praças; o formato das quadras e dos lotes.

A ocupação dessa área e a construção de uma nova paisagem estruturada pelo planejamento regional e pela fundação de uma rede de cidades demonstram a visão que tinha a empresa do papel da cidade e do campo na vida urbana da região.

Palavras-chave: Planejamento urbano, morfologia urbana, forma urbana, Paraná.

\begin{abstract}
The english developer Companhia de Terras Norte do Paraná were responsable for the occupation of Northern Paraná State in Brazil. Between the 1930s and 1960s they designed and built a net of more than sixty new cities as part of a major business: the colonization and occupation of that unexplored territory, which was being prepared for coffee plantation. This paper analyses the design of those new cities, which considered two main localization aspects: be on the top of the hills and close to the just constructed railway. Particular attention is given in this analysis to the basic elements that helped to define each new urban form: the position of institutional buildings in the city; the design of the streets as well as its hierarchy; the form and the position of public spaces and squares; the relation to the natural site; and the urban form properly. The complexity and quality of the different projects represents the company's view of cities' and country role in the area.
\end{abstract}

Key words: Urban planning, urban morphology, urban form, Paraná. 


\section{INTRODUÇÃO}

A Companhia de Terras Norte do Paraná, subsidiária da companhia inglesa Brazil Plantation Syndicate Limited, foi responsável por um grande empreendimento de colonização e desenvolvimento urbano no nork

te do estado do Paraná na primeira metade do século XX. Esse empreendimento tinha como objetivo a venda de glebas rurais destinadas, sobretudo, ao plantio de café. As terras adquiridas pela Companhia junto do governo do estado, a colonizadoras e a posseiros, ultrapassavam os 546.078 alqueires paulistas (Figura 1), localizados junto da bacia do rio Paranapanema entre os vales dos rios Tibagi e Ivaí. O solo fértil oferecia perspectivas promissoras às pessoas interessadas na cafeicultura.

Entretanto, o sucesso da atividade comercial da companhia, assim como o da emergente atividade agrícola, dependia das facilidades que a região podia oferecer - mais precisamente da construção de uma ferrovia e da implantação de cidades para apoiar a atividade agrícola.

De acordo com seu plano geral de ocupação da região, a companhia foi responsável pelo desenho de uma rede de cidades novas, criadas entre os anos 1930 e 1960, que compunham a estrutura do plano de desenvolvimento regional e tinham um duplo papel: ser o lugar dos serviços urbanos e o centro comercial para os negócios da região.

Em 1944 os ingleses deixaram a empresa, e a Companhia de Terras Norte do Paraná passou ao controle de um grupo brasileiro de acionistas. A partir de 1951 passou a denominar-se Companhia Melhoramentos Norte do Paraná. Mesmo assim, o negócio não arrefeceu. Seguindo o plano geral traçado pelos ingleses, a companhia foi fundando cidades, uma rede delas que se estendeu, no tempo e no espaço, de Londrina (a primeira delas, oficialmente datada de 1932) a Umuarama (1955) - a mais distante - e Paiçandu (1960), o último assentamento criado pela empresa. Foram implantados pela companhia 62 núcleos urbanos, sendo 9 patrimônios, 18 distritos, 23 sedes de município e 12 sedes de município com sedes de comarca, afora outros 48 núcleos urbanos implantados por particulares nas terras da companhia ${ }^{2}$.

Conhecidos os traçados dessas cidades, cabe perguntar quais princípios formais regiam cada um desses desenhos urbanos ou quais as estratégias projetuais envolvidas na criação dessas formas urbanas.

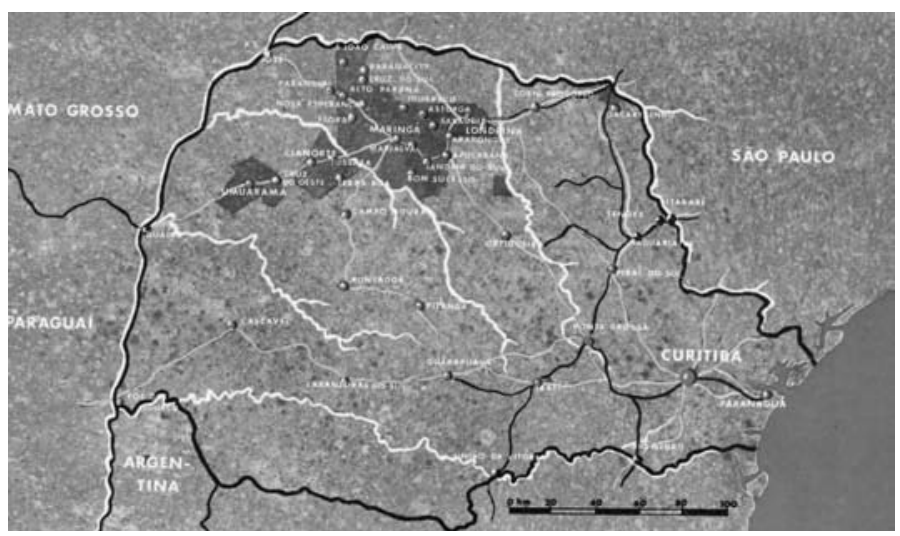

Figura 1:

Terras da Companhia de Terras Norte do Paraná, mais tarde Companhia Melhoramentos Norte do Paraná e principais cidades fundadas em sua propriedade Fonte: CMNP, 1975

Estamos tratando aqui de cidades projetadas, criadas ex-novo, o que quer dizer que seu plano considerou, com bastante liberdade, os objetivos a serem logrados e as condicionantes encontradas e, como em qualquer projeto, atendeu a certas expectativas e certas intenções - inclusive estéticas. É com esse raciocínio que vamos explorar o desenho original dessas cidades riscadas na prancheta e logo construídas no território recém-desbravado.

Apesar dos números e do ritmo de sua criação, as formas dessas cidades planejadas, como seria de esperar, não se repetira. Considerando a explanação da companhia, informando que essas novas cidades se localizavam "em lugares judiciosamente escolhidos" (COMPANHIA, 
1975, p. 137), podemos imaginar que as condições topográficas influenciaram no projeto de cada um dos assentamentos urbanos.

Nota-se que o posicionamento dessas cidades atendeu a dois critérios gerais: acompanhar a linha férrea, no caso das cidades de maior importância, ou as estradas de rodagem, quando não houvesse ferrovia; e situar-se no espigão (Figura 2). Desse modo, veremos que a conformação predominantemente regular desses assentamentos urbanos planejados, fundamentada em sistemas ortogonais, obedece a regras específicas definidas pelo próprio empreendimento comercial, mas também assume certas características de seu suporte físico natural. Daí a razão para as diferenças entre as conformações variadas das cidades.

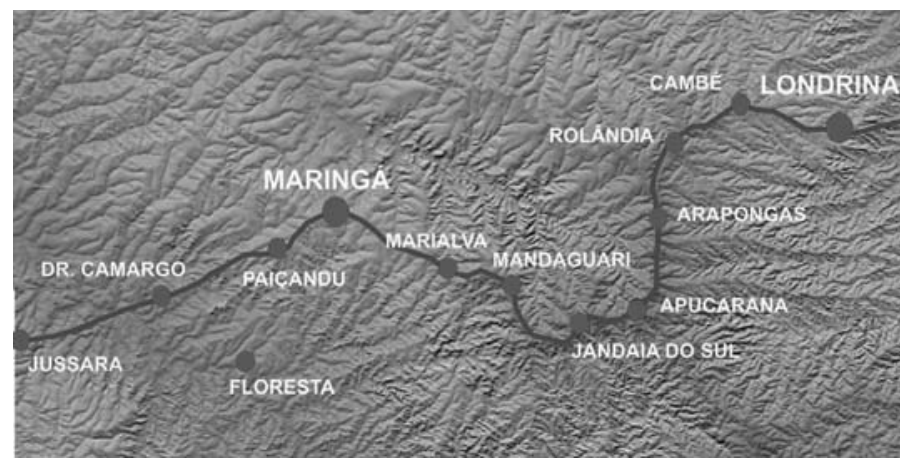

Figura 2:

Relevo das terras da companhia e linha de cumeada onde passa a ferrovia, ao longo da qual se implantou a rede de cidades

Fonte: Embrapa. Organização dos autores

Nesse sentido, o objetivo deste trabalho é averiguar a lógica da formação, a gênese e a estruturação do conjunto de cidades novas fundadas pela companhia, com base nas técnicas de leitura da paisagem e das cidades desenvolvidas pela morfologia urbana. Analisando essas formas urbanas, poderemos avaliar a intervenção do homem e a morfologia do território na conformação de cada uma das cidades novas e na construção da paisagem antrópica.

\section{A ESPACIALIZAÇÃO DO TERRITÓRIO}

A companhia tinha uma estratégia bastante elaborada em termos de planejamento regional e desenho urbano. Para se transformar em espaço habitável e comercializável, o território que ia sendo desbravado foi dividido em pequenas propriedades. Estas estavam delimitadas, de um lado, pelo curso d'água e, do outro, pela via de acesso, sempre posicionada nas linhas de festo, de modo a prover cada lote rural com fácil acesso à água e ao transporte, como se pode notar nas ilustrações apresentadas pela própria companhia (Figuras 3 e 4).

As linhas de festo ou de cumeada marcam os limites entre as bacias hidrográficas, dividindo suas águas nas cotas mais altas, enquanto as linhas de talvegue reúnem as cotas mais baixas da drenagem natural. Esses eixos naturais - festos e talvegues - serão os limites das propriedades rurais que a companhia comercializará; riscadas no chão, do ponto alto da cumeada principal ou de suas ramificações até o curso d'água, aparecerão as divisas laterais dos lotes retangulares postos à venda, redefinindo a paisagem do território em ocupação (Figura 5).

Dessa maneira, a espacialização do território pertencente à companhia é instituída pelo reforço das linhas fundamentais do relevo da região - festos e talvegues - ao qual se sobrepõe um parcelamento rural mais regular, tão prático quanto artificial.

A estruturação da rede de cidades planejada pela companhia se fez, como dissemos anteriormente, com a ferrovia - sua principal ligação. $\bigcirc$ percurso traçado para a linha da Companhia Ferroviária São Paulo-Paraná coincide com as linhas naturais de festo, ou seja, com percursos de cumeada, retomando aquela que parece ser a mais antiga estrutura territorial do espaço antrópico. As estradas vicinais que conduziam às propriedades rurais também adotaram esse mesmo posicionamento. Esses trajetos são como estradas naturais, que 

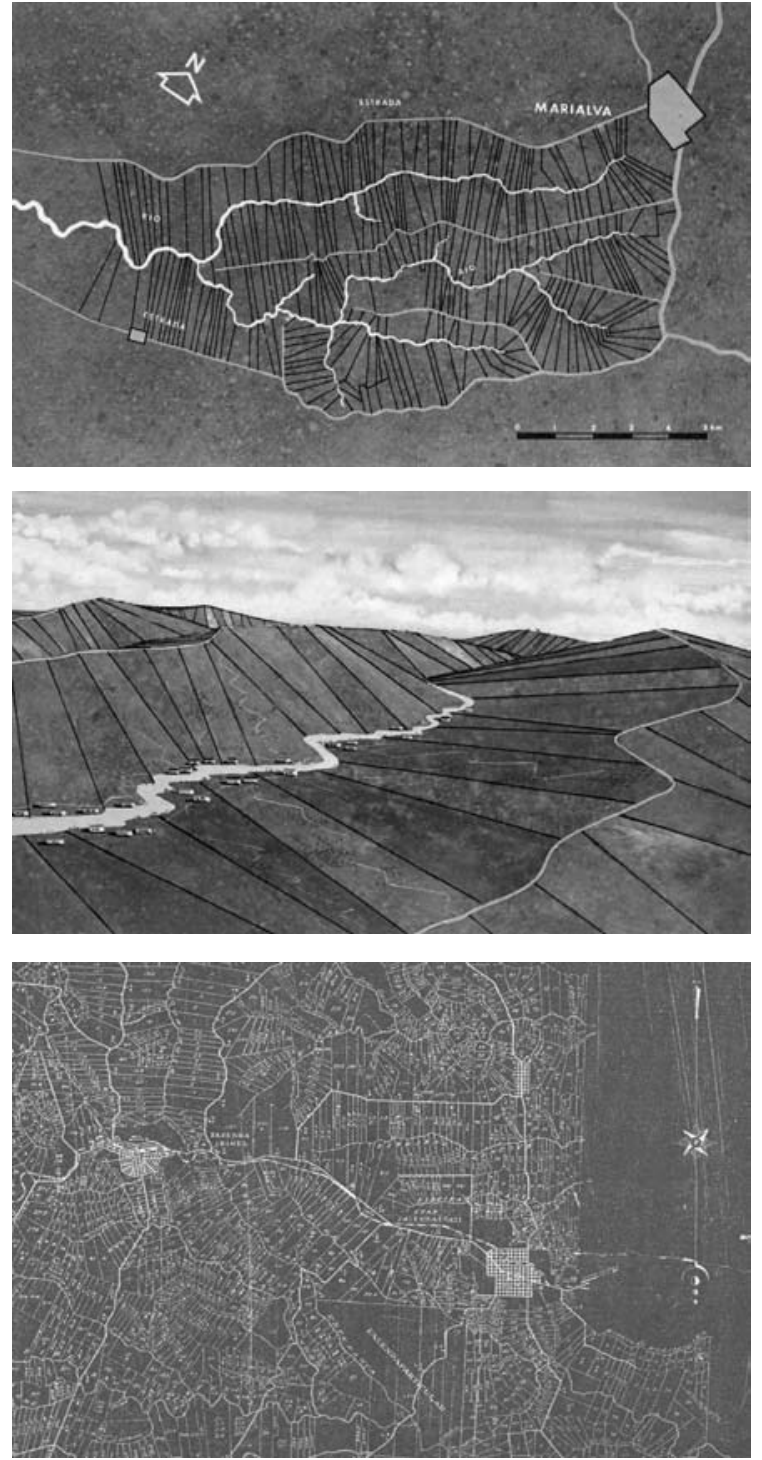

Figura 3:

Parcelamento rural

Fonte: CMNP, 1975

Figura 4:

Ocupação das propriedades rurais

Fonte: CMNP, 1975

Figura 5:

Planta parcial. Colonização das glebas dos ribeirões Três Boccas, Jacutinga, Vermelho e Bandeirantes do Norte, 1934. No mapa se vê, em destaque, Londrina, no canto inferior direito, e Cambé, no centro à esquerda

Fonte: Yamaki, 2003

possibilitam, "para além das capacidades de percurso uma forma de navegação à vista e de conseqüente orientação no percurso" (GUERREIRO, 2005).

A concepção de uma rede de assentamentos urbanos ligados pela ferrovia assegurava o transporte necessário para as pessoas e para a produção agrícola. Como veremos a seguir, a via férrea cruzando o território no topo das colinas era um elemento fundamental na nova paisagem antrópica.

Disposta ao longo da ferrovia e junto das estradas rurais definidas pelo planejamento da companhia, a rede de cidades por elas servida compartilha, conseqüentemente, a mesma linha da cumeada matriz ou das cumeadas secundárias (espigões). Assim, as cidades fundadas pela companhia estão situadas em pontos relevantes da paisagem natural e a ligação entre esses assentamentos urbanos se faz sempre com percursos de cumeada.

Analisando essas formas urbanas, podemos notar que essas cidades estão assentadas no topo das encostas, deitando-se em um de seus lados, o que lhes podia causar algum problema de abastecimento de água, embora garantisse boa drenagem urbana.

Essa escolha de sítios topograficamente dominantes como critério de seleção de locais para a implantação dos assentamentos urbanos é uma prática corrente na tradição urbana 
portuguesa (GUERREIRO, 2005; TEIXEIRA, 2005). Insistindo nas afinidades entre os assentamentos projetados pela companhia e os modelos urbanos portugueses, pode-se notar que ambos apresentam uma forte ligação com o território. Naturalmente não se vê a informalidade ou a organicidade características das cidades portuguesas nas formas urbanas da companhia; trata-se, nesse caso, de cidade planejada, o que historicamente tem implicado características de regularidade, em sistemas ortogonais, enfim, em um pensamento mais abstrato. Contudo, veremos que a morfologia do sítio participou dessas conformações e, muitas vezes, o traçado regular se fragmentou de maneira a adaptar-se à superfície menos regular do território.

\section{A HIERARQUIA DOS ASSENTAMENTOS}

Na constituição de sua rede de cidades, a companhia adotou diretrizes bem definidas: "Cidades destinadas a se tornarem núcleos de maior importância seriam demarcadas de cem em cem quilômetros, aproximadamente. Entre estas, distanciados de 10 a 15 quilômetros um do outro, seriam fundados os patrimônios, centros comerciais e abastecedores intermediários." (CMNP, 1975, p. 76).

Neste sentido, "Para formar o Norte Novo e Novíssimo foram idealizados quatro núcleos habitacionais, fundados sucessivamente, distanciados entre si de aproximadamente cem quilômetros e destinados às grandes cidades do Norte e do Oeste do Paraná: Londrina (1930/1934), Maringá (1947/1951), Cianorte (1953/1955) e Umuarama (1955/1960)" (CMNP, 1975, p. 252).

Entre as quatro grandes cidades, contava-se uma série de assentamentos urbanos menores, formada pelas cidades de médio porte e pelos patrimônios que teriam uma distância ideal, de modo a facilitar a vida nas propriedades rurais das proximidades, permitindo que o morador da área rural pudesse, eventualmente, deslocar-se a pé até eles com uma caminhada de cinco a nove quilômetros, no máximo ${ }^{3}$.

Um esquema semelhante - um conjunto de cidades servido pela via férrea, com paradas espaçadas - era a base da organização do subúrbio inglês, nos começos do século XX, como conta Mumford (2004), e havia sido proposto por Howard (2002) como alternativa para o desenvolvimento de seu projeto da cidade-jardim inglesa. É o que ele chamara de cidades sociais - as quais mais tarde se convencionou como "cidades regionais": uma combinação de recursos e facilidades que só a densa ocupação tornaria possível e que, no caso, seria conquistada pela densa organização, graças ao transporte e à comunicação direta entre cidades interligadas.

Essa ligação entre os assentamentos da companhia beneficiava a relação cidade-campo. Ambos saíam ganhando. Com tal proximidade, os recursos, os serviços e as oportunidades sociais da cidade se acercavam da terra ociosa, das oportunidades financeiras, do trabalho e da vida no campo. Tal como no plano de Howard, as cidades menores gravitam em torno das cidades maiores: os patrimônios se apóiam nas cidades médias que, por sua vez, amparam-se nas quatro grandes cidades.

Lembremos que a companhia classificava seus assentamentos em patrimônios ou cidades, de acordo com o número de quadras. As quatro grandes cidades - Londrina, Maringá, Cianorte e Umuarama - tiveram, como veremos, projetos especiais e desempenharam papel fundamental no planejamento regional seguido pela empresa. Exceto Londrina, que teve um desenho modesto, pois inaugurava um empreendimento bastante ambicioso e não menos arriscado, as outras três cidades maiores foram originalmente planejadas para terem, aproximadamente, 100.000 habitantes, enquanto as cidades menores teriam cerca de 20.000 e os patrimônios não mais de 10.000 residentes.

De acordo com o planejamento da companhia, a venda de propriedades rurais estava atrelada ao comércio de lotes urbanos. Pelas normas do empreendimento, os compradores de propriedades rurais também deveriam adquirir um lote na cidade ou no patrimônio. Havia ainda a obrigatoriedade de edificar-se esse lote urbano em um curto prazo para que as cidades pudessem ser ocupadas mais rapidamente, mostrando-se como atrativo para novos clientes, 
e pudessem ainda desempenhar, efetivamente, seu papel econômico, dando sustentação à vida na região. Nesse sentido, a nova paisagem criada pela companhia era resultado de um pensamento racional e prático, estrategicamente bem definido.

Para levar adiante este estudo, dedicaremo-nos a analisar 14 assentamentos da companhia. Além das quatro cidades principais - Londrina, Maringá, Cianorte e Umuarama -, selecionamos as seguintes cidades de médio porte: Cambé, Rolândia, Arapongas, Mandaguari e Apucarana - pertencentes à fase "inglesa" da companhia - e Jandaia do Sul, já na fase do controle acionário brasileiro da companhia, então denominada Companhia Melhoramentos Norte do Paraná, e os patrimônios Sarandi, Marialva, Jussara e Paiçandu - os quatro últimos da fase nacional do empreendimento ${ }^{4}$. Algumas dessas cidades e desses patrimônios contaram com um desenvolvimento muitas vezes distinto daquele esperado pela companhia, chegando a ultrapassar os limites físicos e populacionais originalmente planejados, tornando-se centros urbanos de grande importância no contexto regional.

\section{O DESENHO DAS FORMAS URBANAS: PADRÃO E PRÁTICA DA COMPANHIA}

A construção dessas cidades envolvia trabalhos diversos, pesados e grosseiros, mas também tarefas mais sutis e sensíveis. Todas estavam a cargo do departamento técnico da companhia.

"O engenheiro Nivaldo Gandra chefiou, durante alguns anos, o departamento técnico da Companhia na cidade de Mandaguari, ex-Lovat, de onde comandava inclusive os volumosos serviços de topografia, contando com a colaboração do engenheiro Waldomiro Babkov" (responsável pelo projeto de Umuarama).

Os dois engenheiros, mesmo sem a formação específica de urbanistas, desempenharam este papel com habilidade, "demarcando lotes, projetando estradas, traçando cidades" (COMPANHIA, 1975, p. 139).

Ainda que "situados em pleno sertão, o projeto e a construção de quase todos (os núcleos habitacionais) foram minuciosamente detalhados, com observância da técnica e da arte do urbanismo, para que se tornassem metrópoles modelares" (CMNP, 1975, p. 252).

Pela análise dos projetos elaborados pelo departamento técnico da companhia, percebe-se que as cidades aí projetadas seguiram um padrão geral comum, embora não exista documentação que confirme esse fato.

Posicionados nos espigões, os assentamentos urbanos projetados pela companhia, como dissemos anteriormente, tomavam posições relevantes e justamente aí tratavam de instalar o centro da cidade.

Londrina (Figura 6), cujo nome registra a origem da Companhia de Terras, não foge a esse padrão. A escolha do sítio para a implantação da primeira cidade projetada pela companhia recaiu sobre um "alto" que impressionou o pessoal do departamento técnico da empresa como um "lugar ideal para uma cidade", daí o desenho oblongo do centro do novo assentamento, acomodado no relevo destacado. A partir desse cume, onde será instalada a igreja, serão abertas ruas ortogonais que se estenderão até os limites da cidade, demarcados, de um lado, pela ferrovia e, do outro, pelo cemitério, determinando uma área urbana de proporções modestas, provavelmente devido à incerteza do negócio em sua fase inicial.

O antropólogo Claude Lévi-Strauss (1996, p. 114) lembra desse desenho urbano simplificado nos relatos de sua passagem pela região.

"Nesses quadriláteros de maneira arbitrária cavados no coração da floresta, as ruas em ângulo reto são, de início, todas parecidas: traçados geométricos, privados de qualidade própria. Entretanto, umas são centrais, outras, periféricas; algumas são paralelas e outras, perpendiculares à via férrea ou à estrada; assim, as primeiras estão no sentido do tráfego, as segundas o cortam e interrompem." 


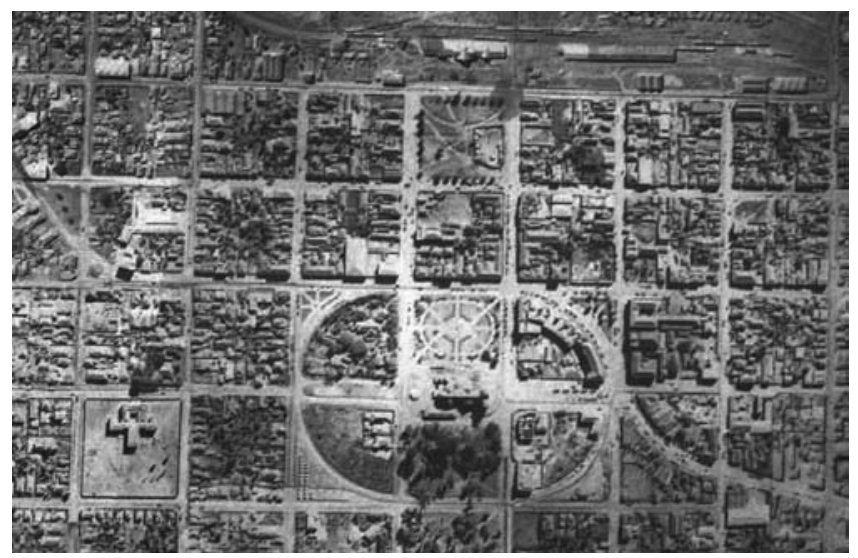

Figura 6:

Londrina, 1949

Fonte: Yamaki, 2003

O desenho urbano de Londrina foi encarregado ao russo Alexandre Razgulaeff, em 1932. Sobre seu projeto formado em geodésia, Razgulaeff diria que a cidade foi "mal projetada", não por culpa sua, já que a imaginara com avenidas de 30 m e ruas com 24 m, mas da própria companhia que, após o envio do projeto à Inglaterra, reduziu essas larguras para ruas de $16 \mathrm{~m}$ e avenidas de $24 \mathrm{~m}$ (YAMAKI, 2003, p. 11). O plano original da cidade tem uma conformação retangular com aproximadamente dois quilômetros em seu lado maior, agrupando 86 quadras. $\bigcirc$ traçado das ruas e quadras se restringe a uma malha ortogonal racional com um elemento excepcional - um elipsóide oblongo central, tangenciado por uma avenida "diagonal" que acompanha o espigão.

Além da escolha de posições relevantes para o centro da cidade, são traços comuns no padrão adotado pela companhia: a existência de uma praça diante da estação ferroviária localizada no limite da cidade; a presença de uma praça central, posicionada em sítio relevante e ligada à praça da estação por um eixo, quer seja um bulevar quer seja uma avenida; o desenho geométrico, preferencialmente ortogonal, como tabuleiro de xadrez; a organização simplificada do espaço urbano por meio do emprego de formas regulares; a hierarquia das vias; o posicionamento de certos elementos urbanos e de alguns edifícios institucionais, fossem eles civis ou religiosos, como o cemitério, o campo de esportes, a igreja, o hospital e a escola, de maneira a estruturar a paisagem urbana.

Os assentamentos resultantes de processos de planejamento, em especial aqueles atrelados à colonização de áreas novas e fundação de novas cidades, costumam apresentar sistemas ortogonais - e a lembrança de Lévi-Strauss nos confirma isso. Essas cidades apresentam malhas regulares, geometrizadas, aparentemente respondendo a uma concepção de espaço racional, intelectual e abstrata, como aquela presente nas cidades romanas de colonização. Padrões regulares e sistemas ortogonais é a resposta mais expedita à tarefa de planejar, criar e fundar cidades novas. Sem embargo, o caso das cidades da companhia foi um tanto diferente. A concepção do traçado urbano desses assentamentos é apenas aparentemente abstrata, devido à forte articulação entre ele e a topografia.

Podemos dizer que o padrão geral da forma urbana estava condicionado a uma prática: sua adaptação ao meio natural suporte. Com isso, os assentamentos urbanos da companhia - cidades grandes, médias ou patrimônios - moldavam-se ao sítio escolhido e, sem romper o padrão geral, assumiam as particularidades topográficas de modo a criar traçados peculiares, resultantes de suas circunstâncias geográficas. É o que podemos notar no desenho de Cambé (Figura 7), por exemplo, com sua conformação multifacetada, quase semicircular, acompanhando as curvas de nível do sítio.

O desenho dessas cidades novas pode ser descrito, em geral, pela praça instalada diante da estação, de onde nascia ortogonalmente o eixo urbano que conduzia ao centro da cidade; aí se abria a praça principal e erguia-se a igreja. Esse eixo tratava de manter uma mesma cota, nivelando a região central da cidade. 


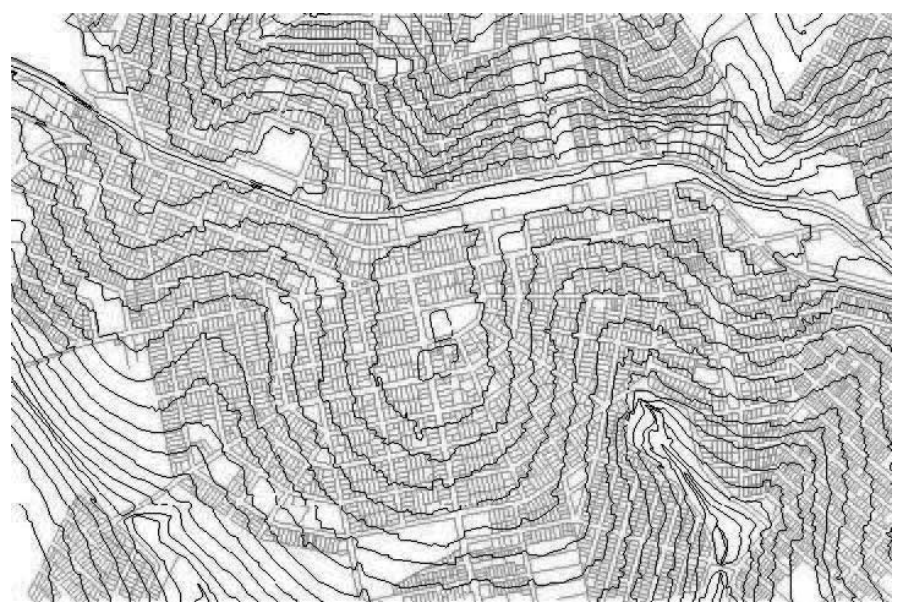

Figura 7:

Cambé. Implantação da cidade e relevo, com destaque para o centro da cidade

Fonte: Acervo dos autores, 2005

Esse esquema foi seguido sempre que a topografia o permitiu. Nesses casos surgiram conformações regulares, geometrizadas e simétricas, com centros bem definidos e organização mais ou menos simétrica dos edifícios institucionais. Vejamos, por exemplo, Jussara (Figura 8), Paiçandu (Figura 9), Sarandi e, de certo modo, também Rolândia e Cambé.

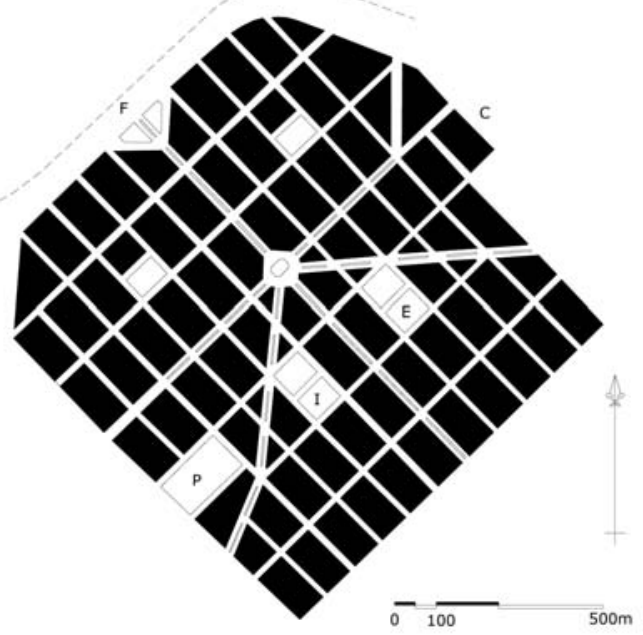

Figura 8:

Jussara. Desenho urbano

( $F$ = estação ferroviária;

$P=$ campo de esportes;

I = igreja;

$E=$ escola;

$\mathrm{C}=$ cemitério)

Fonte: Acervo dos autores, 2005

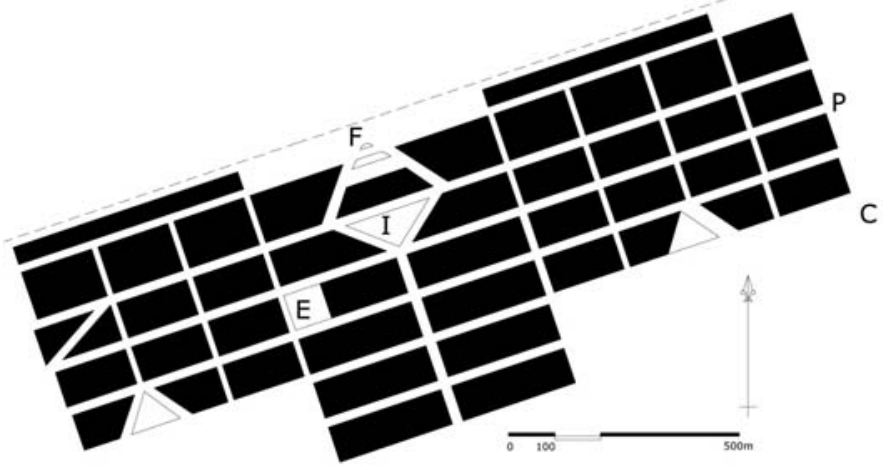

Figura 9:

Paiçandu. Desenho urbano

( $F=$ estação ferroviária;

$P=$ campo de esportes;

I = igreja;

$E=$ escola;

$\mathrm{C}=$ cemitério)

Fonte: Acervo dos autores, 2005 
Quando a topografia era desfavorável, adaptou-se o esquema geral ao sítio. É o caso de Arapongas (Figura 10), cujo eixo surge obliquamente em relação à estação e acompanha o espigão, de modo que a conformação da cidade é linear, condicionada pelas pendentes. Ainda assim temos uma forma regular e um traçado ortogonal. Ou Mandaguari (Figura 11), Apucarana e Jandaia, as quais, todavia em situação mais desfavorável, desenvolvem-se ao longo da ferrovia e possuem uma conformação irregular, resultante da justaposição de vários padrões regulares. Com o eixo urbano riscando uma linha quebrada e a insistência em um arruamento ortogonal, o tecido urbano se fragmenta em setores de traçado xadrez em distintas direções.

Apesar da fragmentação, da descontinuidade e da falta de articulação na malha urbana, esses assentamentos conservaram, preferencialmente, a ortogonalidade no traçado de suas vias.

Apucarana (Figura 12) tem uma situação bem menos favorecida pelo relevo que, de acordo com o padrão da companhia, condicionou sua forma urbana, tornando-a irregular na conformação e fragmentada no traçado. Mesmo nessas condições topográficas mais difíceis, os projetos da companhia não tentaram um desenho sinuoso, o "caminho das mulas", na visão de Le Corbusier, mantendo-se fiel à lógica do caminho reto, direto, rápido e, portanto, prático.

No caso de Umuarama, o desenvolvimento do plano diretor da cidade coube a dois engenheiros da companhia que haviam acompanhado a construção de Maringá e de Cianorte.
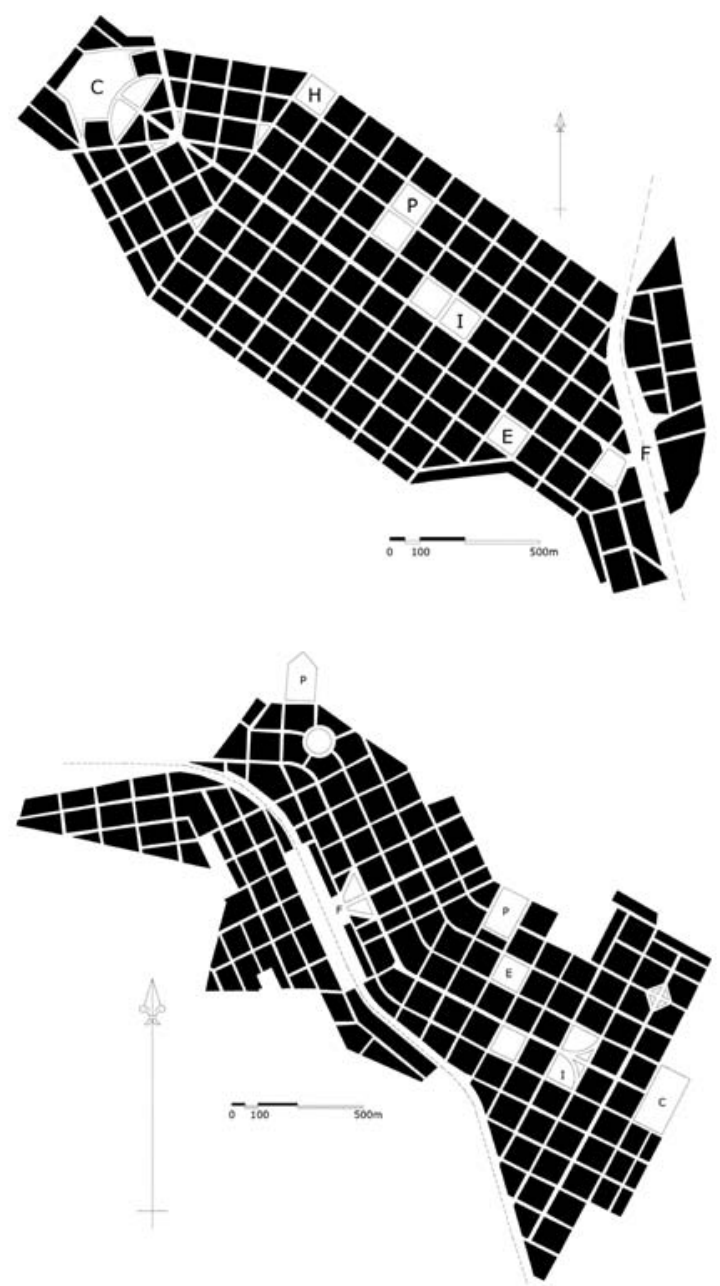

Figura 10:

Arapongas. Desenho urbano

( $F$ = estação ferroviária;

$P=$ campo de esportes;

I = igreja;

$E=$ escola;

$\mathrm{C}=$ cemitério,

$H=$ hospital)

Fonte: Acervo dos autores, 2005

\section{Figura 17:}

Mandaguari. Desenho

urbano

( $F$ = estação ferroviária;

$P=$ campo de esportes;

I = igreja;

$E=$ escola;

$\mathrm{C}=$ cemitério)

Fonte: Acervo dos autores, 2005 


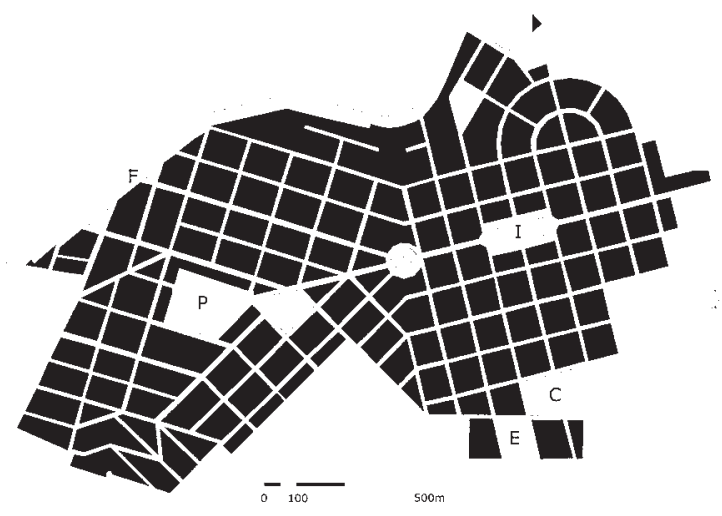

Figura 12:

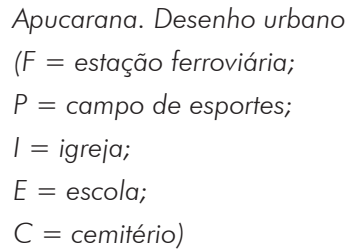

Fonte: Acervo dos autores, 2005

Observando o desenho de Umuarama, parece-nos que aquilo que seus planejadores observaram no traçado das novas cidades que se consolidavam foi aplicado no novo projeto do qual a companhia thes encarregou. Ou seja, a estrutura polinuclear de Maringá e de Cianorte, com seus centros secundários, com suas articulações para as vias de desenho menos regular e as distintas zonas urbanas caracterizadas por configurações destacáveis da malha, serviram de base para o risco de Umuarama. Entretanto, a topografia do sítio no qual se instalou a cidade é consideravelmente irregular, e o desenho urbano geométrico proposto concedeu pouca atenção às pendentes. A configuração do centro da cidade parece ser mais apropriada a uma situação topográfica mais plana; com os aclives e declives que encontramos lá, perde-se a continuidade do traçado e, por conseguinte, a legibilidade do espaço urbano.

Apenas nos projetos de Maringá e de Cianorte veremos que o traçado regular, muitas vezes, deu lugar a um traçado orgânico, para melhor se adaptar às condições topográficas do sítio.

No que se refere ao microparcelamento da área urbana, ou seja, a divisão das quadras em parcelas menores - os lotes -, observa-se a predominância dos formatos regulares e o respeito à ortogonalidade predominante nos traçados da companhia. De maneira geral, o arruamento dos assentamentos urbanos estudados busca acompanhar os pontos cardeais, e as ruas riscadas no sentido norte-sul contêm o maior número de lotes, longitudinalmente dispostos no sentido leste e oeste. Naturalmente, essa regra era abandonada quando se tratava de uma avenida, para onde se voltava a maioria dos lotes de cada quadra, a fim de manter-se a hierarquia e a importância já atribuída a essa via urbana com a largura de 20 m, cinco metros mais larga que as ruas (Figura 13).

Quanto à forma, as praças dessas cidades e patrimônios assumiram, quase sempre, formatos regulares, resultantes das formas geométricas mais simplificadas: retângulos, losangos,

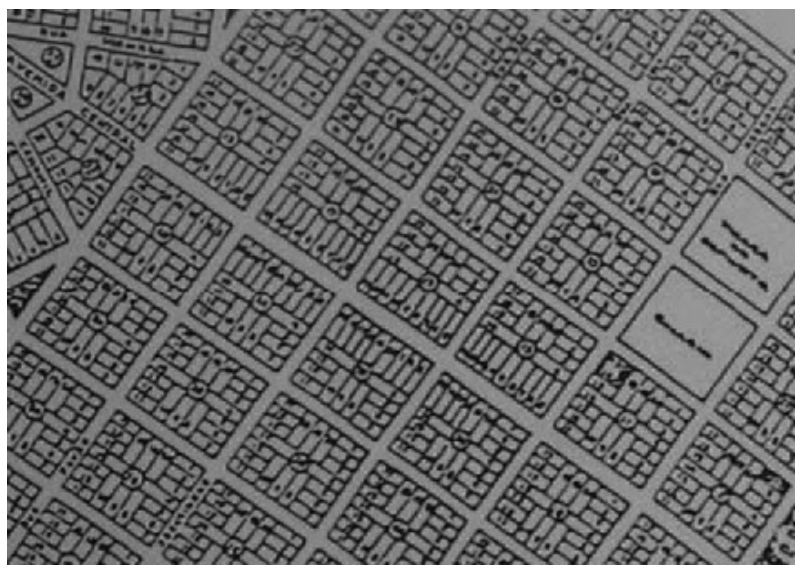

Figura 13:

Arapongas. Detalhe do microparcelamento, com destaque para a praça no lado direito da imagem

Fonte: Acervo dos autores, 2005 
quadrados - soluções da mesma prancheta que elaborou os tabuleiros de xadrez, os quais configuraram as vias urbanas ortogonais. A aparição de campos multifacetados e, principalmente, triangulares como áreas públicas livres acontece menos por uma intenção estética e mais por uma adequação à variação do traçado viário, imposta pelas condições topográficas.

Com efeito, a configuração das praças quase sempre obedeceu à configuração das quadras previamente riscadas, acomodou-se em partes destacadas dessas quadras ou assumiu a forma necessária para articular malhas com orientações diferentes. Poucas vezes as praças se destacam do traçado por meio de conformações diferenciadas, como acontece nas praças centrais de Mandaguari e de Jandaia do Sul e na praça da estação de Rolândia (Figura 14); normalmente, elas se inseriram na regularidade da malha urbana, como é o caso da praça central de Arapongas.

Apenas em Jandaia do Sul a praça principal não é o lugar onde se instala a igreja, que se acomoda em um outro terreno. Nas demais cidades, é sempre reservado um lugar central para a igreja (católica) na principal praça da cidade que, em geral, ocupa os pontos mais altos do sítio urbanizado. Nas cidades nas quais os engenheiros da companhia chegaram a riscar uma proposta de conformação para a praça, definindo canteiros e passeios, a estratégia projetual é consoante com aquela do traçado das cidades: vias retas, formas geométricas, configurações regulares (Figura 15).

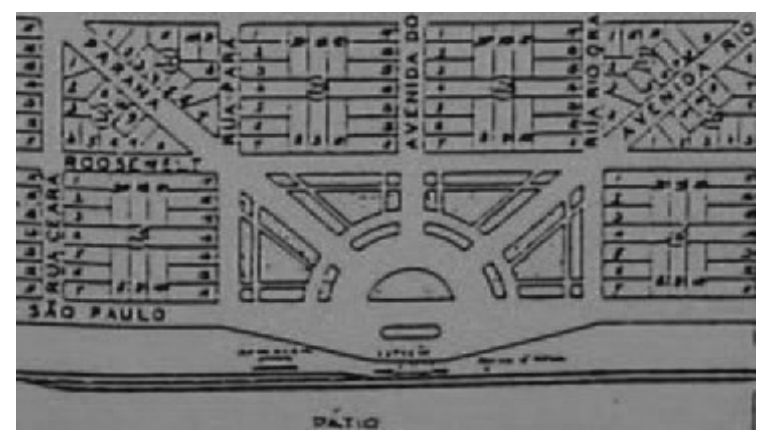

Figura 14:

Rolândia. Detalhe da

praça da estação

Fonte: Acervo dos autores, 2005

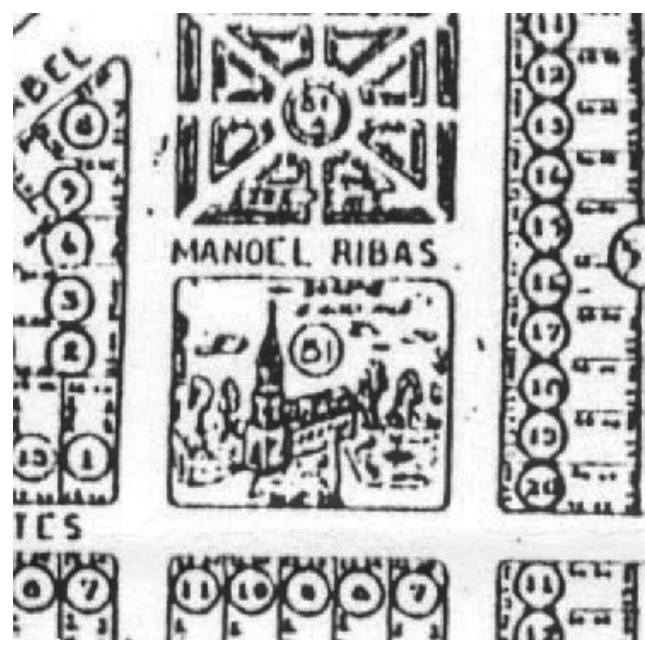

Figura 15:

Jussara. Detalhe de uma das quatro praças centrais da cidade com igreja diante dela

Fonte: Acervo dos autores, 2005

\section{O CASO DE MARINGÁ}

Dentre as cidades projetadas pela companhia, Maringá demonstra uma ruptura. As formas urbanas usuais foram temporariamente abandonadas em favor de um novo padrão, sem que se interrompesse a prática adotada. Depois dos projetos de Maringá e Cianorte, exceções à regra, como veremos, o padrão da companhia foi restabelecido, o que se pode 
notar pelo desenho de Jussara.

Na época do projeto de Maringá, a companhia, já então com controle acionário de brasileiros, parece ter sido mais generosa e com estrito interesse imobiliário, menos determinante no desenho urbano da nova cidade em questão. Nem o projeto de Maringá nem o de Cianorte foram elaborados pelo departamento técnico da companhia: ficaram a cargo do engenheiro Jorge de Macedo Vieira, que trabalhara com Barry Parker na Cia. City de Loteamentos, em São Paulo. Como se sabe, Parker havia sido sócio de Raymond Unwin e juntos haviam desenhado a primeira cidade-jardim inglesa. Macedo Vieira foi influenciado pela "arte de projetar cidades" inglesa e não hesitou em aplicar, no anteprojeto de Maringá, alguns dos princípios dessa arte, especialmente aqueles publicados por Unwin, em 1909, no livro Town planning in practice.

Apesar da proposta formal radicalmente diferente das cidades anteriores, a prática da companhia foi mantida no projeto de Maringá (Figura 16). A forma urbana se moldou no terreno. Para o traçado dessa cidade tomou-se como referência três condicionantes fundamentais: 0 traçado da linha férrea no sentido leste-oeste e dois pequenos vales ao sul. Esses dois vales foram delimitados como parques urbanos, preservando as duas nascentes aí existentes, e, entre eles, posicionou-se o centro da vida comunitária, em uma área praticamente plana, figurando como o elemento principal do plano, de acordo com as diretrizes de Unwin (1984).

A morfologia do sítio foi determinante para o desenho da cidade, uma vez que foi a partir dela, da pendente do terreno e da configuração topográfica, que se definiu a forma urbana alongada e única. É essa a individualidade defendida por Unwin (1984, p. 22) como uma das características mais positivas da forma urbana.

No desenho de Maringá - assim como no de Cianorte -, ainda se percebe a localização da cidade dada pela linha férrea; o posicionamento das principais praças (a da estação de estrada de ferro e a central) em locais relevantes, ligadas por um bulevar e constituindo um eixo monumental; e os edifícios públicos atuando como elementos estruturadores da imagem urbana. Entretanto, abandonou-se o padrão da companhia quando se adotou o traçado
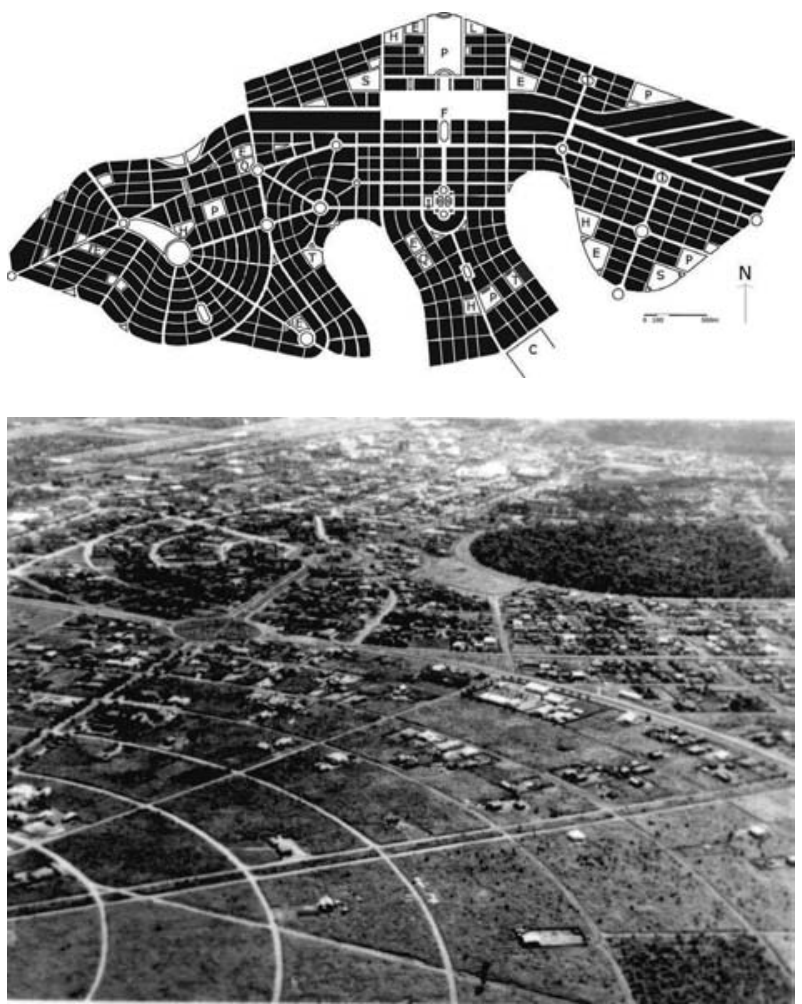

Figura 16:

Maringá. Desenho urbano (E - escola; $H$ - hospital; $P$ - campo de esportes; $Q$ - parque infantil; $T$ - internato; $S$ - instituto profissional; L - asilo; I - igreja; F - estação ferroviária; $\mathrm{C}=$ cemitério) Fonte: Acervo, dos autores, 2005
Figura 17:

Maringá. Ruas curvas

Fonte: Acervo do Departamento de Patrimônio Histórico da Prefeitura do Município de Maringá 
orgânico como diretriz para as vias principais.

Percebe-se aí que o diálogo mais efetivo com o ambiente natural demandou um traçado irregular na maior parte da malha urbana (Figura 17), que, não obstante, pôde cobrar regularidade, simetria e rigidez no centro da cidade, o principal elemento da composição, cuja finalidade, caráter e importância do espaço público requeriam certo formalismo e monumentalidade, de modo a garantir o "caráter artístico" do desenho urbano e forjar a individualização do desenho da cidade, a partir das características naturais do entorno.

Nota-se, no anteprojeto de Vieira, a intenção de respaldar as praças de Maringá com edifícios ao seu redor, construindo aquela sensação de fechamento que tanto Unwin como Sitte mencionam com entusiasmo.

Ao final do eixo monumental se encontra o centro cívico, arrematado por uma praça semicircular, que deveria abrigar um edifício público em forma de crescent, mas acabou por dar lugar à catedral (Figuras 18 e 19).

É notável a hierarquia entre as vias principais e secundárias, diferenciadas pela largura (20, 30, 35 e 40 metros), pela eventual presença do canteiro central e variedade de espécies que viria a ser empregada na arborização urbana (Figuras 20 e 21). Esta, além de criar um microclima mais adequado à ocupação humana, tinha a clara intenção de dotar a cidade de uma imagem urbana particular.

No anteprojeto de Macedo Vieira, a cidade está subdividida em três zonas residenciais (principal, popular e operária), zona industrial, zona comercial, dependências e armazéns da estrada de ferro e os núcleos comerciais, sempre com um limite preciso - bosque ou avenida.

Assim como a cidade tem seu centro, cada uma das zonas ou bairros residenciais tem seu centro secundário, formado por um espaço público livre rodeado por edifícios comerciais, uma

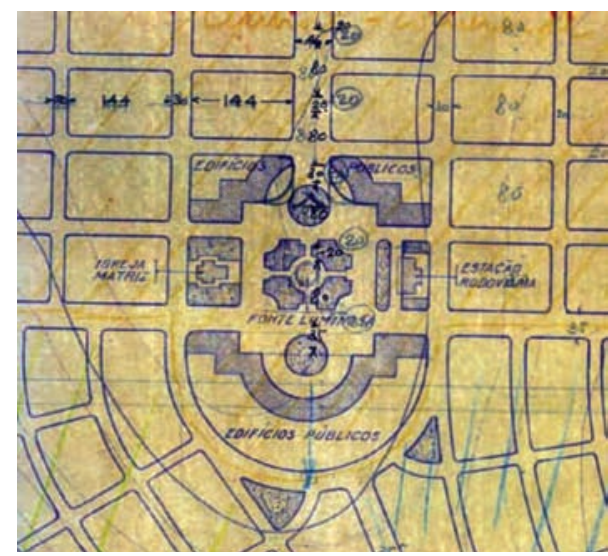

Figura 18: Maringá. Detalhe da praça central com crescent. Anteprojeto de Jorge de Macedo Vieira

Fonte: Acervo do Museu da Bacia do Paraná

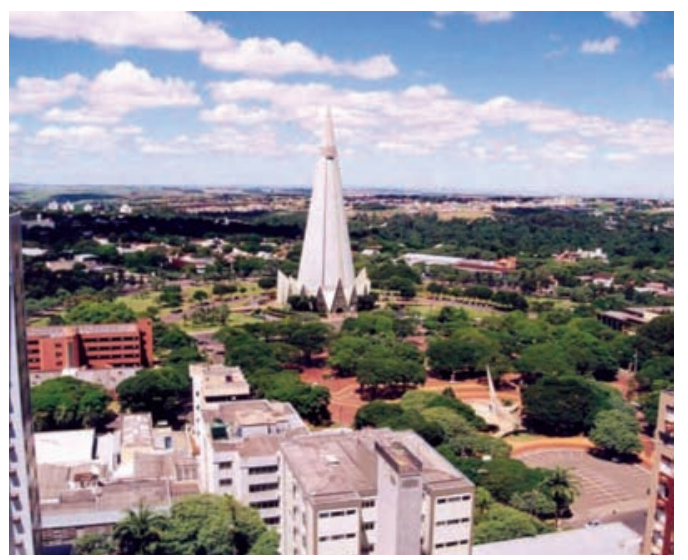

Figura 19: Maringá. Ocupação atual com a catedral Fonte: Acervo dos autores, 2005

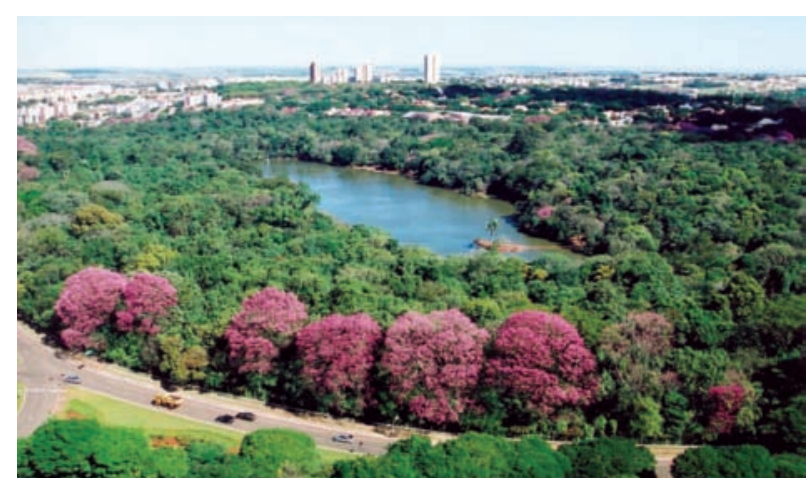

Figura 20:

Maringá. Arborização urbana

Fonte: Acervo dos autores, 2005 
espécie de "praça fechada", constituindo cada centro secundário um ponto focal, elemento fundamental para a imagem urbana (Figura 22). $O$ desenho da cidade mostra uma estrutura polinuclear, articulada em uma hierarquia muito clara entre o elemento principal do plano e seus centros secundários (Figura 23).

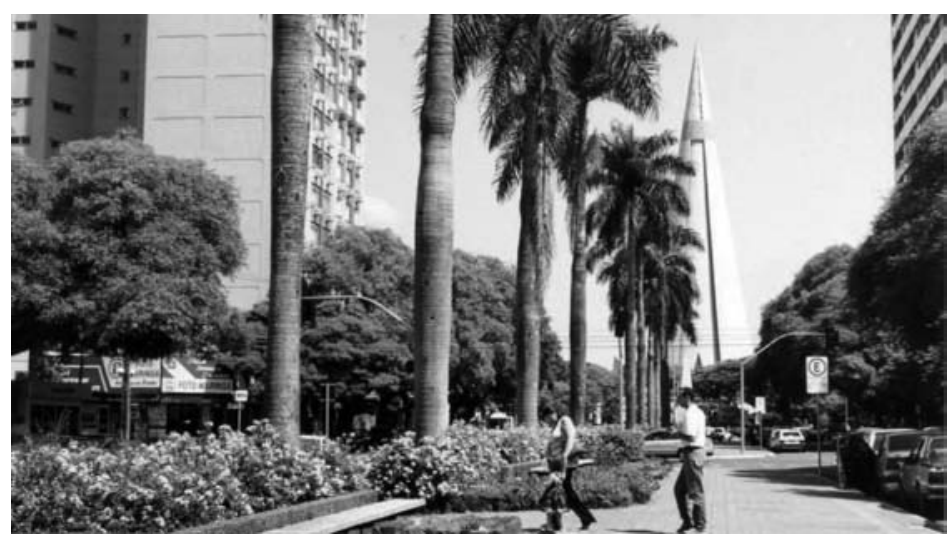

Figura 21:

Maringá. Arborização urbana

Fonte: Acervo dos autores, 2005
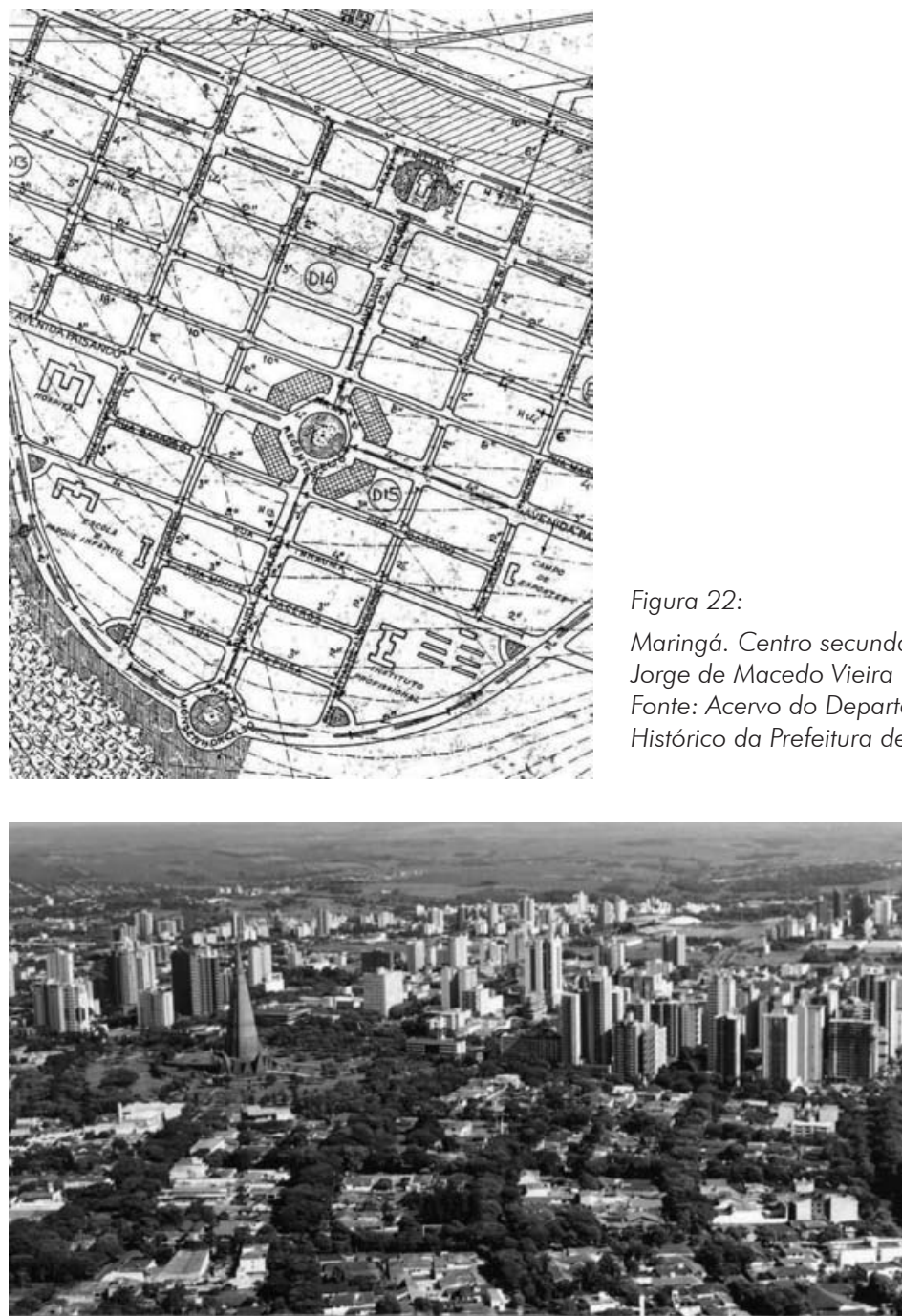

Figura 22:

Maringá. Centro secundário. Anteprojeto de Jorge de Macedo Vieira

Fonte: Acervo do Departamento de Patrimônio

Histórico da Prefeitura de Maringá
Figura 23:

Maringá. Região central

Fonte: Acervo dos autores, 2005 


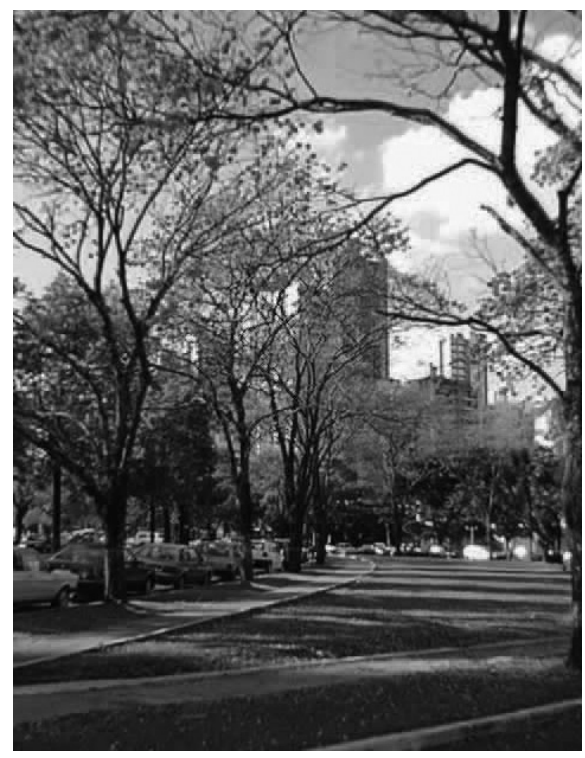

Figura 24:

Maringá. Região central

Fonte: Acervo dos autores, 2000

Pode-se dizer que se trata de uma nova expressão para a vida comunitária, esteticamente mais rica que as formas urbanas projetadas anteriormente pela companhia (Figura 24).

\section{CONCLUSÃO: A PAISAGEM CONSTRUÍDA}

Os projetos urbanos da companhia, riscados no solo limpo da vegetação natural, foram desenvolvidos a partir das condicionantes locais (o sítio e o relevo, a via férrea e a estação ferroviária) e do plano geral de empresa (rede de cidades, número e tamanho dos assentamentos).

A rede urbana conectada pela ferrovia fomentaria a relação cidade-campo e a hierarquia dos assentamentos urbanos interligados equilibraria e compensaria as questões locais no âmbito regional, fossem elas de infra-estrutura, funcionais, sociais ou mesmo econômicas.

A construção das formas urbanas aqui relacionadas tratou de responder, como pudemos notar, tanto a procedimentos técnicos (a atenção à drenagem urbana; o posicionamento da cidade junto da ferrovia ou das estradas; o respeito à topografia) como a princípios artísticos (a simetria em alguns traçados; a configuração do centro da cidade; a posição e o agrupamento dos edifícios institucionais; a hierarquia das vias; os motivos formais da organização das quadras), ainda que a resposta dada a uns e outros nem sempre fosse equivalente.

Houve um padrão para a estruturação dos assentamentos urbanos projetados pela companhia - e classificados em cidades, cidades menores e patrimônios - embora a prática projetual da empresa fosse adaptar esse padrão às particularidades topográficas do sítio onde seriam implantados os novos assentamentos.

Tanto o posicionamento desses assentamentos urbanos quanto o trajeto da ferrovia que os conectava e os percursos das estradas rurais seguiam as linhas de cumeada ou os espigões. A conformação dessas cidades buscava sempre a instituição de um centro comunitário que fosse, no sentido amplo do termo, o ponto alto da vida urbana.

Em geral, atendendo aos interesses comerciais do empreendimento, o desenho dessas cidades obedeceu à lógica do modo estrito, direto, prático e econômico, atendendo apenas às necessidades mais básicas. Apesar de notarmos algumas intenções estéticas nas formas urbanas projetadas pela companhia, temos de admitir que os procedimentos técnicos e práticos prevaleceram.

Curiosamente, o padrão dos projetos urbanos da companhia é rompido com os desenhos orgânicos de Maringá e Cianorte, baseados nos princípios formais da cidade-jardim inglesa. Se as idéias de Unwin e Parker significavam, no contexto europeu, o resgate das qualidades da 
cidade antiga e a observação de motivos da forma urbana tradicional, nos projetos da companhia elas passaram a representar algo diferente: a conformação de uma cidade moderna, inovadora, progressista, tal como a companhia anunciava esses seus produtos à venda.

De toda sorte, a região experimentou um grande desenvolvimento, não apenas vinculado à produção agrícola, mas, em grande parte, graças ao plano global de desenvolvimento da companhia, com sua rede de cidades. Infelizmente, a linha férrea não é mais o principal meio de transporte, sobrevivendo, atualmente, somente para o transporte da produção agrícola. As cidades cresceram com novas áreas urbanas, desatentas e indiferentes aos seus planos originais.

Contudo, pode-se ainda perceber claramente os diferentes níveis de qualidade urbana das cidades e da paisagem antrópica que elas construíram: entre aquelas projetadas de modo mais prático e mais técnico e aquelas mais elaboradas, com espaços urbanos mais sugestivos, prazerosos, ricos e memoráveis.

\section{Notas}

(1) Uma versão preliminar deste texto foi apresentada no International Seminar on Urban Form (ISUF), em Londres, 2005.

(2) Estudando os projetos da companhia, pudemos notar que eram consideradas cidades aqueles assentamentos que continham mais de 100 quadras (Cambe, 100; Rolândia, 122; Arapongas, 168; Apucarana, 144; Jandaia do Sul, 116; e Mandaguari, 161) e patrimônios os quais continham um número inferior de quadras (Marialva, 93; Sarandi, 40; Jussara, 90; e Paiçandu, 44).

(3) Londrina e Cambé distavam 13 quilômetros; Cambé e Rolândia, 10; Rolândia e Arapongas, 12; Arapongas e Aricanduva, 9; Aricanduva e Apucarana, 8; Apucarana e Pirapó, 7; Pirapó e Cambira, 7; Cambira e Jandaia do Sul, 5; Jandaia do Sul e Mandaguari, 10; Mandaguari e Marialva, 15; Marialva e Sarandi, 10; Sarandi e Maringá, 7; Maringá e Paiçandu, 15; Paiçandu e Água Boa, 15, e assim sucessivamente até Cianorte. Ver levantamento da linha ferroviária Apucarana-Guaíra no Museu da Bacia do Paraná, Universidade Estadual de Londrina.

(4) Londrina (1930), Cambé (1932), Rolândia (1932), Arapongas (1935), Mandaguari (1937) e Apucarana (1937) pertencem à fase inglesa do empreendimento; Maringá (1947), Cianorte (1953), Umuarama (1955), Jandaia do Sul (1951), Sarandi (1948), Marialva (1951), Jussara (1955) e Paiçandu (1960) foram fundados na fase nacional do empreendimento.

\section{Bibliografia}

ANDRADE, Carlos Roberto Monteiro. Ressonâncias do tipo cidade-jardim no urbanismo de cidades novas no Brasil. In: SEMINÁRIO DE HISTÓRIA DA CIDADE E DO URBANISMO, 6, 2000, Natal. Anais... Natal: UFRN, 2000.

BARNABÉ, Marcos Fagundes. Organização espacial do território e o projeto da cidade: O caso da Companhia de Terras Norte do Paraná. 1989. Dissertação (Mestrado) - EESC/USP, São Carlos-SP, 1989.

BONFATO, Antonio Carlos. Jorge de Macedo Vieira. O orgânico e o geométrico na prática urbana (1920-1960). Revista Brasileira de Estudos Urbanos e Regionais, Rio de Janeiro, v. 5, n. 2, 2003

CARVALHO, Luiz Domingos Moreno de. O posicionamento e o traçado urbano de algumas cidades implantadas pela Companhia de Terras Norte do Paraná e sucessora, Companhia Melhoramentos Norte do Paraná. 2000. Dissertação (Mestrado em Geografia) - Universidade Estadual de Maringá, Maringá-PR, 2000.

COMPANHIA Melhoramentos Norte do Paraná (CMNP). Colonização e desenvolvimento do Norte do Paraná. Paraná: (s. n.), 1975.

GUERREIRO, Maria Rosália. A lógica territorial na gênese e formação das cidades brasileiras. $\bigcirc$ caso de Ouro Preto. Urbanismo de origem portuguesa, n. 3. Disponível em: <http://www.urban.iscte.pt/revista/numero3/artigos/ artigo_11.htm>. Acesso em: 12 set. 2005.

HOWARD, Ebenezer. Cidades-jardins de amanhã. 2. ed. São Paulo: Hucitec/Annablume, 2002.

LAMAS, José M. Ressano Garcia. Morfologia urbana e desenho da cidade. Lisboa: Fundação Calouste Gulbenkian, 1999.

LÉVI-STRAUSS, Claude. Tristes trópicos. São Paulo: Companhia das Letras, 1996. 
LYNCH, Kevin. A imagem da cidade. São Paulo: Martins Fontes, 1999.

MIRANDA, E. E. de (Coord.). Brasil em relevo. Campinas: Embrapa Monitoramento por Satélite, 2005. Disponível em: <http://www.relevobr.cnpm.embrapa.br>. Acesso em: 12 set. 2005.

MORRIS, A. E. J. Historia de la forma urbana. 4. ed. Barcelona: Gustavo Gilli, 1992.

MUMFORD, Lewis. A cidade na história. 4. ed. São Paulo: Martins Fontes, 2004.

REGO, Renato Leão. O desenho urbano de Maringá e a idéia de cidade-jardim. Acta Scientiarum, Paraná, v. 23, n. 6, p. 1.569-1.577, 2001.

et al. Reconstruindo a forma urbana: Uma análise do desenho das principais cidades da Companhia de Terras Norte do Paraná. Acta Scientiarum, Paraná, v. 26, n. 2, p. 141 -150, 2004.

; MENEGUETTI, Karin Schwabe. The construction of the urban form: The design of new cities in Brazil as part of an agriculture development business. In: INTERNATIONAL SEMINAR ON URBAN FORM, 2005, Londres. Proceedings... Londres: INTBAU/The Princess Foundation, 2005.

SITTE, Camillo. A construção de cidades segundo princípios artísticos. São Paulo: Ática, 1992.

TEIXEIRA, Manuel C. Os modelos urbanos portugueses da cidade brasileira. Urbanismo de origem portuguesa, n. 3. Disponível em: <http://www.urban.iscte.pt/revista/numero3/artigos/artigo_07.htm>. Acesso em: 12 set. 2005.

UNWIN, Raymond. La practica del urbanismo. Una introducción al arte de proyectar ciudades e barrios. Barcelona: Gustavo Gilli, 1984.

WOLFF, Silvia Ferreira dos Santos. Jardim América. O primeiro bairro-jardim de São Paulo e sua arquitetura. 1998. Tese (Doutorado) - Faculdade de Arquitetura e Urbanismo da Universidade de São Paulo, São Paulo, 1998.

YAMAKI, Humberto. Cidades novas norte-paranaenses. In: SEMINÁRIO DE HISTÓRIA DA CIDADE E DO URBANISMO, 6, 2000, Natal. Anais... Natal: UFRN, 2000. . Iconografia londrinense. Mapas parciais 1930-1950. Londrina: Humanidades, 2003. 